\title{
Bacteriophage P1
}

National Cancer Institute

\section{Source}

National Cancer Institute. Bacteriophage P1. NCI Thesaurus. Code C14301.

A double-stranded DNA virus that infects E. coli and other enteric bacteria. Additionally, this phage is used in molecular biotechnology as a cloning vector for eukaryotic DNA. 